\title{
A Comparison of the Oxygen Release from Roots of Thalia and Pontederia in Constructed Wetland Wastewater Treatment Systems
}

\author{
Chan DONG \\ College of Applied Chemistry \\ Nanjing Polytechnic Institute \\ College of Water Conservancy and Hydropower \\ Engineering \\ Hohai University \\ Nanjing, P.R.China \\ e-mail: chan_dong@163.com
}

\author{
Yinghao HUANG \\ Geotechnical Engineering Department \\ Nanjing Hydraulic Research Institute \\ Nanjing, P.R.China \\ e-mail: ythuangyinghao@163.com
}

\begin{abstract}
To investigate the ability of oxygen release from roots of different vegetation, and explain the mechanism. This paper tested the variation of oxygen release rate from roots of Thalia and Pontederia using a titanium (III) citrate buffer. The results shows that oxygen release rates with the same condition were higher for Thalia. This difference is caused by the special structure of Thalia. The aerenchyma of Thalia is good at the oxygen transport. The results of this paper can help us to choose better vegetation species for wastewater treatment.
\end{abstract}

Keywords-constructed wetland; vegetation; oxygen release

\section{INTRODUCTION}

Constructed wetlands (CWs) are artificial wetlands which are designed and constructed to manipulate the natural processes to treat wastewater[1]. Macrophytes play several roles in engineered ecosystems helping to stabilize the surface of the beds, provide good conditions for physical filtration and insulate the surface against coldness[2-4]. Organic matter production and plant uptake of nutrients as well as root-zone oxygen and organic carbon release were identified as key factors influencing nutrient transformation and sequestration in low-loaded systems[3-5]. A recent innovation in horizontal sub-surface flow CWs has been the inclusion of forced aeration to promote aerobic conditions and ammonia removal[6-8]. This has proved successful in the US[9] and testing is producing successful results in the UK[10] and Europe[11]. However, little was known about the ability of oxygen release from roots with different species. And the reason of the difference is still unclear. This paper aims to test the ability of oxygen release from roots of different vegetation, and explain the mechanism. It can help us to optimize the operation of wetland systems.

\section{Materials AND MethodS}

\section{A. Experimental Materials and Procedures}

Young Thalia dealbata and Pontederia cordata were collected from a natural wetland located in Xuanwu Lake, Nanjing. After collection, the plants were transplanted to individual plastic pots filled with respective nutrient solutions (self-made nutrient solutions with average concentrations of COD and $\mathrm{TN}$ of $50 \mathrm{mg} / \mathrm{L}$ and $15 \mathrm{mg} / \mathrm{L}$, respectively) for three weeks before sowing. The plants were removed from the pots and their roots were gently washed free of debris twelve hours before experiments. The plants (Thalia dealbata) had 20-80 adventitious roots which varied in length from $15-64 \mathrm{~cm}$ and were up to $0.121 \pm 0.013 \mathrm{~cm}$ $(\mathrm{n}=96)$ in diameter. Their height of above-ground was 65$80 \mathrm{~cm}$. And the plants (Pontederia cordata) had 34-95 adventitious roots which varied in length from $12-38 \mathrm{~cm}$ and were up to $0.108 \pm 0.036 \mathrm{~cm}(\mathrm{n}=126)$ in diameter. Their height of above-ground was $52-75 \mathrm{~cm}$.

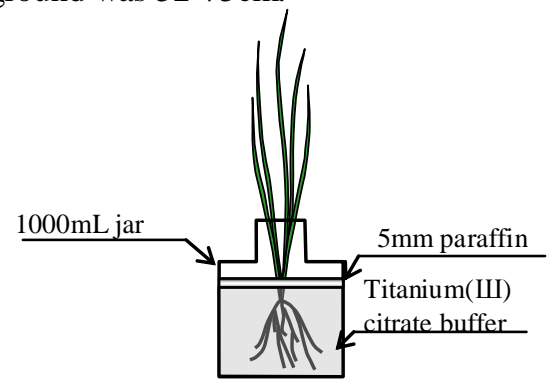

Figure 1. Schematic sketch of the root oxygen release rate detecting device.

Oxygen release from the roots was examined using a non-phytotoxic titanium (Ш) citrate buffer, which allows root oxygen release measurements in a reducing, oxygenscavenging solution with a low redox potential[12,13]. The $1000 \mathrm{~mL}$ jar was initially filled with $900 \mathrm{~mL}$ distilled water, and the water was then sparged with $\mathrm{N}_{2}$ gas for $60 \mathrm{~min}$ to remove any oxygen dissolved in the water. Sparging with $\mathrm{N}_{2}$ gas was continued while titanium (Ш) citrate stock solution (made by $0.2249 \mathrm{~g}$ citric acid and $8 \mathrm{~mL} \mathrm{TiCl}_{3}$ ) were added. The basal part of the shoot was wrapped with tinfoil to prevent the oil from infiltrating the aerenchyma. The stirring from the sparging was necessary for complete mixing. The roots of plants were submerged in the solution. A $5 \mathrm{~mm}$ thick layer of paraffin oil was placed on top of the solution to prevent re-aeration from the atmosphere. It ensured that the roots were the only possible source of oxygen entry into the chamber. The root chamber was shielded from light using a tight-fitting tinfoil cover. Blank jars without plants were also prepared in similar way to serve as negative control. Figure. 
1 shows the experimental device used in the investigation of the root oxygen release rate. The experimental device was exposed to the open air and natural light in a sealed area outside the laboratory building. Light intensity was measured every 1 hour using a luminometer (MODEL ZDS-10F-2D). The unit of light intensity is lux. Details of the experimental set-up are shown in table I.

TABLE I. LIGHT INTENSITY, TEMPERATURE AND HUMIDITY DURING EXPERIMENTS

\begin{tabular}{|c|c|c|c|c|c|c|}
\hline Experimental date & \multicolumn{2}{|c|}{$\begin{array}{c}\text { PAR } \\
{\left[\mu \mathrm{mol} \cdot \mathrm{m}^{-2} \cdot \mathrm{s}^{-1}\right]}\end{array}$} & \multicolumn{2}{c|}{$\begin{array}{c}\text { Temperature } \\
{\left[{ }^{\circ} \mathrm{C}\right]}\end{array}$} & \multicolumn{2}{c|}{$\begin{array}{c}\text { Humidity } \\
{[\%]}\end{array}$} \\
\hline & Average & range & Average & range & Average & range \\
\hline 4 September & 319.6 & $0-1316.9$ & 28 & $24-35$ & 49 & $24-60$ \\
\hline 2 October & 391.5 & $0-1141.4$ & 24 & $17-33$ & 41 & $12-59$ \\
\hline 3 October & 370.9 & $0-1068.9$ & 23 & $18-32$ & 39 & $12-57$ \\
\hline
\end{tabular}

Sample number is 24 . PAR is photosynthetically active radiation. One lux is $0.019 \mu \mathrm{mol} \cdot \mathrm{m}-2 \cdot \mathrm{s}-$

\section{B. Sampling and Analytical Methods}

Since the oxygen released from the roots was oxidized by $\mathrm{Ti}^{3+}$ in titanium (Ш) citrate buffer, rates of root oxygen release could be calculated from the rate of decrease in the concentration of $\mathrm{Ti}^{3+}$ in the jars. As the brown titanium (Ш) citrate solution gradually became clear during oxidation, the samples were taken every 1 hour using a small syringe and the absorbance at $527 \mathrm{~nm}$ was measured immediately using a spectrophotometer. The absorbances of the samples were compared to those of solutions with a known concentration of $\mathrm{Ti}^{3+}$. At the same time, the light intensity, temperature and humidity were examined. The relation of $\mathrm{Ti}^{3+}$ and $\mathrm{O}_{2}$ is described in the Eq. (1). It is seen that $1 \mathrm{~mol} \mathrm{O}_{2}$ is consumed when $4 \mathrm{~mol} \mathrm{Ti}^{3+}$ were reduced. The oxygen consumption $\left(\Delta \mathrm{O}_{2}, \mathrm{mg}\right)$ is thus calculated using Eq. (2). Thereafter, the root oxygen release rate $\left(V_{O}, \mu \mathrm{molg}^{-1} \mathrm{~h}^{-1}\right)$ could be calculated using Eq. (3).

$$
\begin{gathered}
\mathrm{O}_{2}+4 \mathrm{Ti}^{3+}+4 \mathrm{H}^{+}=4 \mathrm{Ti}^{4+}+2 \mathrm{H}_{2} \mathrm{O} \\
\Delta \mathrm{O}_{2}=\frac{32 \times V \times\left(C_{0}-C_{e}\right)}{4 \times 47.73}
\end{gathered}
$$

Where $V$ is the volume of titanium (Ш) citrate buffer, 0.9L. $C_{0}, C_{e}$ are the initial and end $\mathrm{Ti}^{3+}$ concentration, respectively.

$$
V_{O}=\frac{\Delta O_{2} \times 1000}{24 \times 32 \times \text { Root dry weighs }}
$$

\section{RESUlTS AND DISCUSSION}

Values for root oxygen release were obtained from $\mathrm{Ti}^{3+}$ concentrations measured in the test jars, via the above equations. Diurnal fluctuations in oxygen release and PAR are shown in Figure 2 and 3. Our results reveal a significant difference in rate of root oxygen release between day and night. Oxygen release increased gradually with increasing light intensity during the morning. A decrease in oxygen release occurred during the decreasing light intensity of the afternoon. At night, oxygen release rate approached $0 \mu \mathrm{molg}$ ${ }^{1} \mathrm{~h}^{-1}$. In all three experiments, the start and end times of oxygen release were closely related to light. The maximum oxygen release rate $\left(256.5-325.7 \mu^{-10} \lg ^{-1} \mathrm{~h}^{-1}\right.$ and 154.6$285.6 \mu \mathrm{molg}^{-1} \mathrm{~h}^{-1}$ for Thalia and Pontederia respectively) was observed during the daytime at 15:00 hrs, while the maximum light intensity was observed at 13:00 hrs. The maximum value of PAR ranged from 1068.9 to 1316.9 mmolm $\mathrm{s}^{-1}$. Clearly, the peak of root oxygen release occurred after the peak of light intensity.

We show that rate of oxygen release depends largely on light intensity and exhibits a diurnal periodicity. Variations in oxygen release and light intensity follow unimodal patterns during the daytime and can be accurately described by the Gaussian function.

We can use of light intensity data in prediction of the quantity of oxygen likely to be released using Gaussian function[15], which is in the form of follows:

$$
V_{O}=a e^{-\frac{\left(t-t_{\text {omax }}\right)^{2}}{c^{2}}}
$$

Where $t$ is time (4:00am 20:00pm); $a$ (in Gaussian function) is the maximum value of oxygen release rate in a whole day; $t_{\text {Omax }}$ is the location of the symmetry axis in Gaussian function; $c$ expresses the gradient of Gaussian function. Decrease in $c$ is relative to steep Gaussian function while increase in $c$ is relative to gentle Gaussian function.

Light intensity data during daytime (4:00am-20:00pm) also follow Gaussian function, it can be described as:

$$
P A R=b e^{-\frac{\left(t-t_{\text {Lmax }}\right)^{2}}{d^{2}}}
$$

Where $P A R$ is the photosynthetically active radiation, $\mu \mathrm{mol} \cdot \mathrm{m}^{-2} \cdot \mathrm{s}^{-1} ; t$ is time; $b$ is the peak value of $P A R$ in a whole day; and $d$ is the gradient of unimodal.

For Thalia system, the relationship between parameters $a$ and $b, c$ and $d$ are as follows:

$$
a=29.65 e^{0.00166 b} \quad c=8.24 e^{-0.3518 d}
$$

The parameters for Pontederia are as follows:

$$
a=24.22 e^{0.0018 b} \quad c=2.3184 e^{0.1719 d}
$$

Modeling parameters obtained are shown in Table II. Then, the root oxygen release rate was predicted and jointly illustrated in Fig. 4. The results reveal that our model data closely match our experimental values. The oxygen release rate increased exponentially with increased $P A R$. And the oxygen release rates with the same condition were higher for Thalia. Because its parameter " $a$ ", which means the maximum value of oxygen release rates in one day-night, was higher. This difference is caused by the special structure 
of Thalia. Oxygen is produced through photosynthesis, and oxygen transport from the sections of the plant above the ground through the rhizome into the fine roots is effected by specific areas of tissue formed in the plant known as the aerenchyma. The aerenchyma of Thalia is good at the oxygen transport.
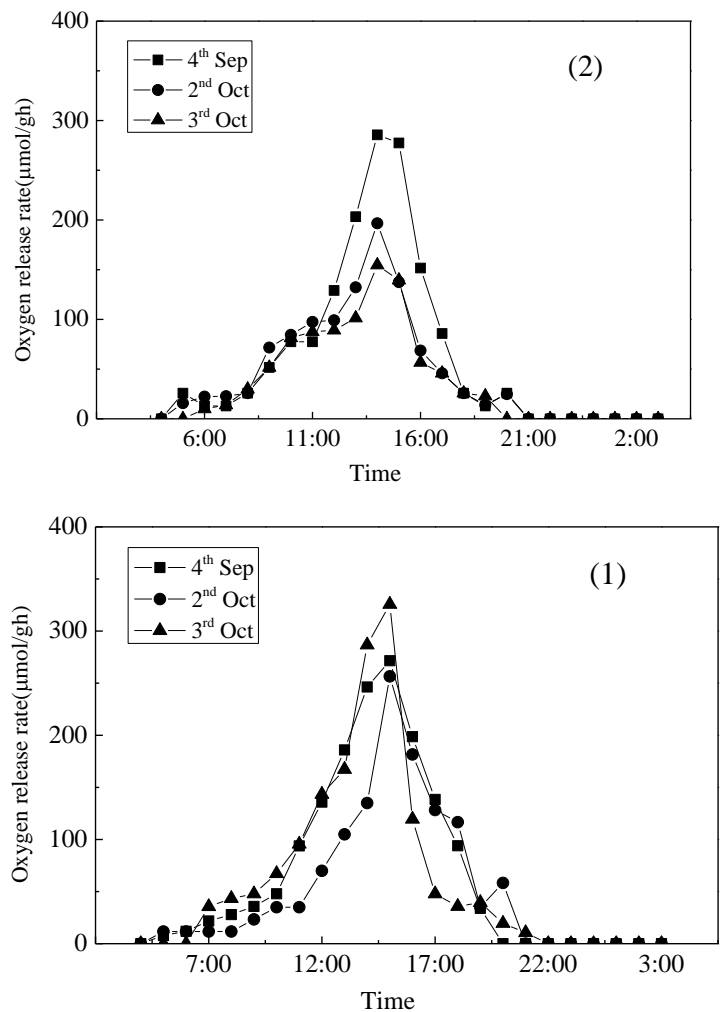

Figure 2. Diurnal fluctuation of oxygen release from the roots of Thalia (1) and Pontederia (2).

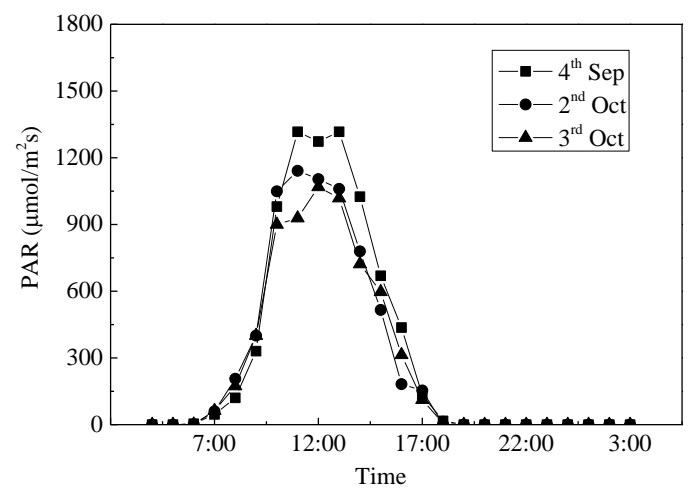

Figure 3. Daily changes of photosynthetically active radiation.

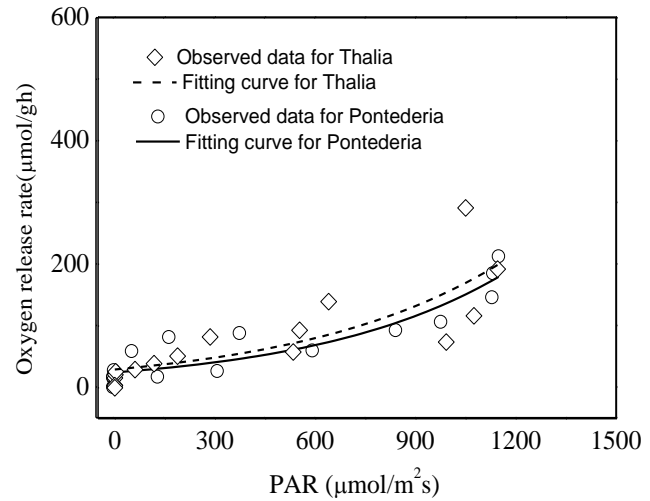

Figure 4. The effect of light intensity on root oxygen release rate.

TABLE II. THE PARAMETERS OF MODELING

\begin{tabular}{ccccccc}
\hline & PAR & \multicolumn{3}{c}{$\begin{array}{c}\text { Oxygen release by } \\
\text { Thalia }\end{array}$} & \multicolumn{2}{c}{$\begin{array}{c}\text { Oxygen release by } \\
\text { Pontederia }\end{array}$} \\
\cline { 2 - 8 } Date & $\begin{array}{c}\mathrm{b} \\
\left(\mu \mathrm{mol} \cdot \mathrm{m}^{-2} \cdot \mathrm{s}^{-1}\right)\end{array}$ & $\mathrm{d}$ & $\begin{array}{c}\mathrm{a} \\
\left(\mu \mathrm{molg}^{-1} \mathrm{~h}^{-1},\right.\end{array}$ & $\mathrm{c}$ & $\begin{array}{c}\mathrm{a} \\
\left(\mu \mathrm{molg}^{-1} \mathrm{~h}^{-1},\right.\end{array}$ & $\mathrm{c}$ \\
\hline $\begin{array}{c}\text { 4st } \\
\text { September }\end{array}$ & 1214 & 3.137 & 251.6 & 3.361 & 215.4 & 3.975 \\
\hline $\begin{array}{c}\text { 2nd } \\
\text { October }\end{array}$ & 1214 & 3.137 & 201 & 3.212 & 215.4 & 3.975 \\
\hline $\begin{array}{c}\text { 3rd } \\
\text { October }\end{array}$ & 1092 & 3.33 & 278.9 & 2.598 & 172.9 & 4.110 \\
\hline
\end{tabular}

\section{CONCLUSIONS}

The results reveal that oxygen release rates with the same condition were higher for Thalia. Firstly, oxygen release rate increased exponentially with increased $P A R$ in both of the two systems. However, the rates of oxygen released from roots were higher for Thalia than Pontederia all the time. And than the parameter " $a$ " for Thalia was higher. This difference is caused by the special structure of Thalia. The aerenchyma of Thalia is good at the oxygen transport. The results of this paper can help us to choose better vegetation species for wastewater treatment.

\section{ACKNOWLEDGEMENTS}

This work was financially supported by the National Natural Science Foundation of China (51308184), humanities and Social Science Projects of Nan Jing College of Chemical Technology (NJCC-2014-YB-05), the Natural Science Foundation of Jiang'su University (16KJB610017), Jiangsu province environmental protection scientific research subject (2016058), research project of Nanjing Polytechnic Institute (NHKY-2015-03), and Jiangsu Students' Project for Innovation and Entrepreneurship Training (201512920006Y).

\section{REFERENCES}

[1] J. Chen, X.D. Wei, Y.Sh. Liu, G.G. Ying, Sh.Sh. Liu, L.Y. He, H.Ch $\mathrm{Su}$, L.X. Hu, F.R. Chen, Y.Q. Yang, Removal of antibiotics and antibiotic resistance genes from domestic sewage by constructed wetlands: Optimization of wetland substrates and hydraulic loading, Sci. Total Environ. 565, 240-248 (2016)

[2] T. Carballeira, I. Ruiz, M. Soto, Effect of plants and surface loading rate on the treatment efficiency of shallow subsurface constructed wetlands, Ecol. Eng. 90, 203-214 (2016). 
[3] H. Brix, Do macrophytes play a role in constructed treatment wetlands? Water Sci. Technol. 35, 11-17 (1997).

[4] J. Vymazal, Plants used in constructed wetlands with horizontal subsurface flow: a review, Hydrobiologia 674, 133-156 (2011).

[5] C. Tanner, Plants as ecosystem engineers in subsurface-flow treatment wetlands, Water Sci. Technol. 44, 9-17 (2001).

[6] E. Butterworth, A. Richards, M. Jones, H. Brix, G. Dotro, B. Jefferson, Impact of aeration on macrophyte establishment in subsurface constructed wetlands used for tertiary treatment of sewage, Ecol. Eng. 91, 65-73 (2016)

[7] C. Ouellet-Plamondon, F. Chazarenc, Y. Comeau, J. Brisson, Artificial aeration to increase pollutant removal efficiency of constructed wetlands in cold climate, Ecol. Eng. 27, 258-264 (2006).

[8] L. Zhang, Y. Liu, Y. Shen, H. Liu, Y. Xiong, Effect of limited artificial aeration on constructed wetland treatment of domestic waste water, Desalination 250, 915-920 (2010).

[9] R. Kadlec, S. Wallace, Treatment Wetlands, second ed. Taylor \& Francis Group, FL, USA (2009).
[10] E. Butterworth, G. Dotro, M. Jones, A. Richard, P. Onunkwo, Y Narroway, B. Jefferson, Effect of artificial aeration on tertiary nitrification in a full-scale subsurface horizontal flow constructed wetland, Ecol. Eng. 54, 236-244 (2013).

[11] J. Nevala, Effect of Design on Treatment Performance, Plant Nutrition and Clogging in Subsurface Flow Treatment Wetlands, Aarhus University, Aarhus (Ph.D. Thesis, 2012).

[12] B.K. Sorrell, W. Armstrong, On the difficulties of measuring oxygen release by root systems of wetland plants, Journal of Ecology, 82, 177-183 (1994).

[13] N. Dorthe, K. Jespersen, Sorrell, Brian, Brix, Hans, Growth and root oxygen release by Typha latifolia and its effects on sediment methanogenesis, Aquatic Botany 61, 165-180 (1998).

[14] X.Q. Mei, Z. H. Ye, M. H. Wong, The relationship of root porosity and radial oxygen loss on arsenic tolerance and uptake in rice grains and straw, Environ. Pollut. 157, 2550-2557 (2009).

[15] C. Dong, W. Zhu, M. Gao, L. F. Zhao, J. Y. Huang, Y. Q. Zhao. Diurnal Fluctuations in Oxygen Release from Roots of Acorus calamus Linn in a Modeled Constructed Wetland, J. Environ. Sci. Health., Part A 46, 224-229 (2011). 